\title{
Prognostic value of ZEB-1 in solid tumors: a meta-analysis
}

\author{
Borong Chen ${ }^{1 \dagger}$, Baisheng Chen ${ }^{2 \dagger}$, Zhipeng Zhu ${ }^{1+}$, Weipeng Ye ${ }^{3}$, Junjie Zeng ${ }^{1}$, Gang Liư ${ }^{4}$, Shengjie Wang ${ }^{1}$, \\ Jin Gao', Guoxing $\mathrm{Xu}^{5^{*}}$ and Zhengjie Huang ${ }^{1,3^{*}}$
}

\begin{abstract}
Background: Zinc-finger E-box binding homeobox 1 (ZEB-1) plays crucial roles in epithelial-to-mesenchymal transition during tumor carcinogenesis. Published studies have examined the potential value of ZEB-1 as a biomarker for the prognosis of cancer. Nevertheless, the prognostic significance of ZEB-1 in human solid tumor remains inconclusive. Therefore, we performed the present meta-analysis to evaluate the prognostic value of ZEB-1 in patients with solid tumors.
\end{abstract}

Methods: The 13 included studies (1616 patients) were exact electronic searched from Web of Science, PubMed and EBSCO until September 2018. Pooled hazard ratios (HR) and the corresponding 95\% confidence intervals (Cl) for overall survival (OS) were analyzed through random or fixed effects models. Univariate and multivariate analyses were independently performed. Subgroup analyses, heterogeneity and publication bias were investigated to further enhance reliability.

Results: This research indicated that elevated expression of ZEB-1 significantly predicted worse OS in patients with solid tumors. In the univariate analysis, the pooled HR for OS was 1.66 (95\% Cl: $1.45-1.90 ; P<0.01$ ). Meanwhile, in multivariate analysis, the pooled HR for OS was 2.28 ( $95 \% \mathrm{Cl}: 1.58-3.30 ; P<0.01)$. Begg's funnel plot and Begg's test did not show evidence of significant publication bias, both in univariate analysis and multivariate analysis.

Conclusions: High expression of ZEB-1 was associated with poorer OS, suggesting that ZEB-1 may be a potential biomarker for the prediction of prognosis, and a novel therapeutic target in human solid tumors.

Keywords: ZEB-1, Overall survival, Solid tumor, Meta-analysis

\section{Background}

Zinc finger E-box binding homeobox 1 (ZEB-1) is a transcription factor, belongs to the human ZEB family. It is also known as dEF1, ZFHX1A, Nil-2-a, TCF8, AREB6, or BZP [1]. Functionally, ZEB-1 is implicated in multiple processes during the development of neural crest cells, lymphopoiesis, and neurogenesis. [2] Recently, further studies revealed that ZEB-1 plays a significant role in epithelial to mesenchymal transitions (EMT) during

\footnotetext{
* Correspondence: xuguoxing2005@163.com; huangzhengjie@xmu.edu.cn †Borong Chen, Baisheng Chen and Zhipeng Zhu contributed equally to this work.

${ }^{5}$ Department of Endoscopy Center, First Affiliated Hospital of Xiamen University, Xiamen, China

${ }^{1}$ Department of Gastrointestinal Surgery, Xiamen Cancer Hospital of The First Affiliated Hospital of Xiamen University, 55 Zhen Hai Road, Si Ming District, Xiamen 361003, Fujian Province, China

Full list of author information is available at the end of the article
}

tumor invasion and metastasis in various types of human cancer. [3] EMT is a biological process characterized by the conversion from an epithelial cell phenotype to a mesenchymal phenotype, which is closely related to enhanced cell motility and invasion. [4] Research demonstrated that ZEB-1 promotes the process of EMT through regulation of the relevant protein binding domains, such as the p300-P/CAF binding domain, Smad interaction domain, and C-terminal-binding protein interaction domain. $[2,5]$ Furthermore, ZEB-1 facilitates EMT by suppressing the cell adhesion molecule Ecadherin, which is a critical transmembrane protein in maintaining the epithelial phenotype. [6, 7] This specific regulatory pathway is established as a hallmark of EMT. A study conducted by $\mathrm{Hu}$ et al. [8] indicated that ZEB-1through down-regulation of p21 transcription to

(c) The Author(s). 2019 Open Access This article is distributed under the terms of the Creative Commons Attribution 4.0 International License (http://creativecommons.org/licenses/by/4.0/), which permits unrestricted use, distribution, and reproduction in any medium, provided you give appropriate credit to the original author(s) and the source, provide a link to the Creative Commons license, and indicate if changes were made. The Creative Commons Public Domain Dedication waiver (http://creativecommons.org/publicdomain/zero/1.0/) applies to the data made available in this article, unless otherwise stated. 
promote the proliferation of breast cancer cells. Jia et al. [9] suggested that aberrant expression of ZEB-1in gastric cancer was associated with tumor stage, depth of invasion and poor differentiation. Accumulating evidence has demonstrated that ZEB-1was abnormally expressed in a variety of human solid tumors, and promoted an aggressive during carcinogenesis.

An increasing number of studies have shown that over-expression of ZEB-1 was related to shorter survival in several types of human solid tumors, including colorectal cancer, [10-12] gastric cancer, $[13,14]$ hepatocellular carcinoma, $[15,16]$ pancreatic cancer, $[17,18]$ esophageal squamous cell carcinoma, $[19,20]$ oral cavity carcinoma, [21] and intrahepatic cholangiocarcinoma. [22] Nevertheless, the prognostic significance of ZEB-1 in human solid tumor remains uncertain. Therefore, the aim of this comprehensive meta-analysis was to evaluate the prognostic role of ZEB-1expression for patients with solid tumor. This study was designed to assess the clinical value of ZEB-1 in terms of overall survival (OS) in patients with solid tumors, and shed more light on the development of ZEB-1 targeted therapy and prognostic indicators in this setting.

\section{Methods}

\section{Literature search and selection criteria}

An electronic literature retrieval of studies investigating the expression of ZEB-1 and clinical prognosis in Web of Science, PubMed and EBSCO was conducted until September 2018 to identify latent eligible articles. The search keywords for the subject heading terms were: "Zinc-finger E-box binding homeobox 1" or "ZEB-1" or "dEF1" or "ZFHX1A" or "Nil-2-a" or "TCF8" or "AREB6" or "BZP" and "cancer" or "tumor" or "neoplasm" or "carcinoma," and "prognosis" or "survival". Only studies involving patients with solid tumors were included. Collectively, 840 entries were identified.

The inclusion criteria were as follows: (1) diagnosis of human solid tumor; (2) the role of ZEB-1 in the tumor progression must be investigated; (3) description of the relevance of ZEB-1 expression to OS; (4) availability of data to obtain a hazard ratio (HR) and $95 \%$ confidence interval (CI); (5) publication in English. The exclusion criteria were as follows: (1) duplication; (2) conference abstract, review, and book; (3) basic research and animal experiments; (4) lack of usable data. There were two independent investigators (B.R Chen and Z.P Zhu) carefully scrutinized each candidate article. Disagreements were resolved through discussion between the two investigators until a consensus was reached.

\section{Data extraction and quality assessment}

The following data were extracted by two independent investigators (B.S Chen and W.P Ye): name of first author, year of publication, country, type of cancer, case number, sex of patients, median age of patients, detection method, cut-off value of the overexpression of ZEB1, follow-up period, survival analysis, obtained of HR, and Newcastle-Ottawa Scale (NOS) scores. Each HR and corresponding 95\% CI were extracted based on the tables or Kaplan-Meier curves describing groups of patients with high or low expression of ZEB-1. Besides, all of the included researches were cohort studies. The NOS [23] was used to estimate the quality of the included studies in our meta-analysis. Studies with a NOS score $\geq 6$ were defined as high quality research. Finally, any conflicting results were resolved through by discussion between the two authors.

\section{Statistical analysis}

Survival outcomes were the most essential endpoints. Therefore, the HR and 95\% CI were directly extracted from the original publications or calculated by means of the Kaplan- Meier method according to Tierney's method. [24] Subsequently, the RevMan 5.3 analysis software (Cochrane Collaboration, Copenhagen, Denmark) was used to evaluate the prognostic value of ZEB-1 in solid tumors. The heterogeneity of pooled results was assessed through Higgin's $I^{2}$ statistics and Cochran's $Q$ test. $[25,26]$ $\mathrm{I}^{2}<50 \%$ and $P>0.05$ indicated the absence of severe heterogeneity and hence, a fixed-effects model (Mantel-Haenszel) was adopted. Otherwise, random-effects model (DerSimonian and Laird) was be performed $\left(\mathrm{I}^{2} \geq 50 \%\right.$ and $P \leq 0.05)$. Subgroup and sensitivity analyses were performed to evaluate the sources of heterogeneity. Begg's funnel plot was conducted to estimate the risk of publication bias through STATA 12.0 software. A $P<0.05$ denoted statistical significance.

\section{Results \\ Study characteristics}

The detailed steps of literature selection are shown in Fig. 1. Initially, 840 relevant studies were identified. Eventually, 13 eligible articles published between 2011 and 2017 were included in this meta-analysis, and their main features are summarized in Table 1. A total of 1616 patients with solid tumors from China, Japan, United States of America, Germany, and Norway were analyzed. Besides, there were involved in seven types of solid tumors, including three colorectal cancer, [10-12] two gastric cancer, $[13,14]$ two hepatocellular carcinoma, [15, 16] two pancreatic cancer, $[17,18]$ two esophageal squamous cell carcinoma, $[19,20]$ one oral cavity carcinoma, [21] and one intrahepatic cholangiocarcinoma. [22] The included studies were performed to analyze OS. HR and 95\% CI data were directly obtained from six studies. Data from remaining seven studies 


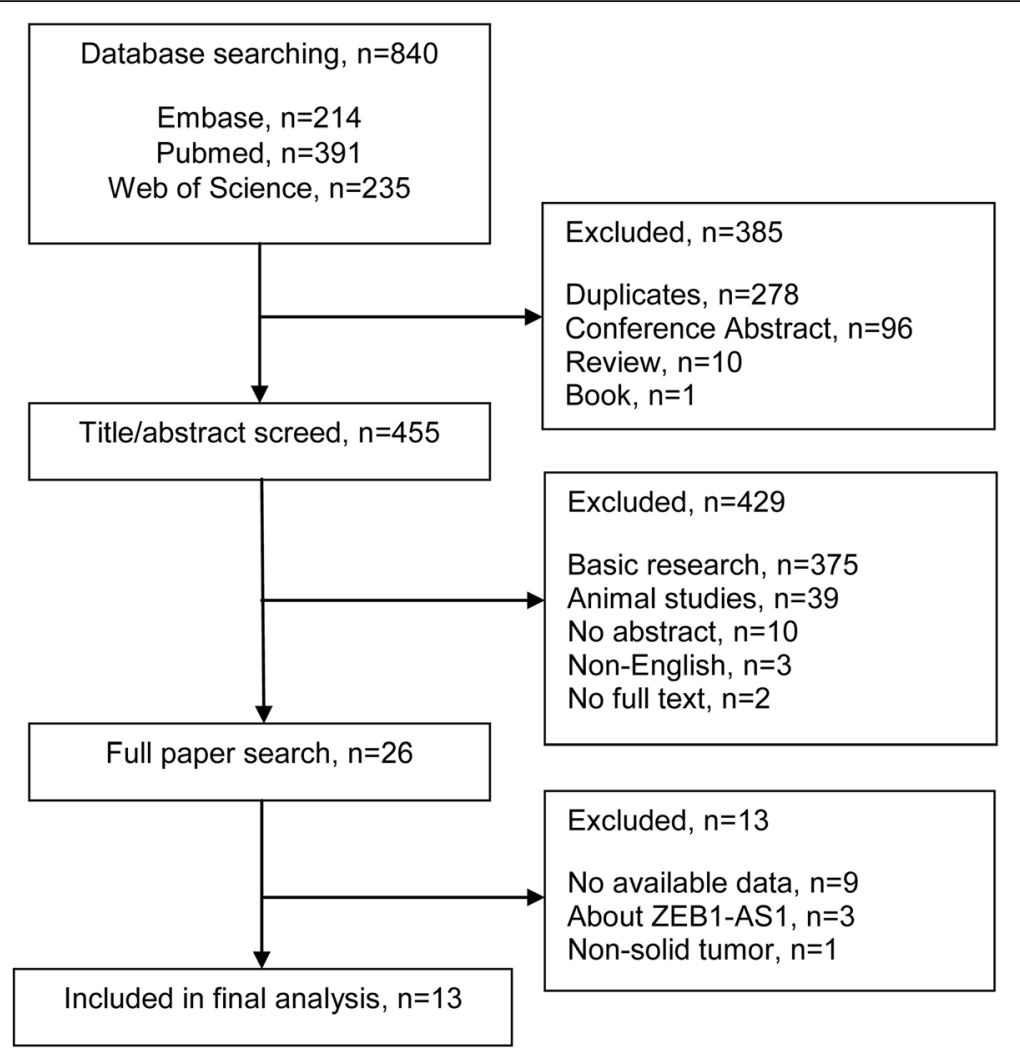

Fig. 1 Flow diagram of the literature selection process

were extracted using Kaplan-Meier survival curves. All 13 studies reported a NOS score $>6$ (Table 2).

\section{Overall survival}

The combined analysis of published data from nine univariate analyses suggested that a high expression level of ZEB-1 was correlated with poor OS in patients with solid tumors (pooled HR: 1.66; 95\% CI: 1.45-1.90). Notably, there was no significant heterogeneity reported $\left(P=0.39, \mathrm{I}^{2}=5 \%\right)$, thus, a fixed-effects model was performed (Fig. 2).The combined analysis of published data from seven multivariate analyses demonstrated that overexpression of ZEB-1 was associated with worse survival outcome in patients with solid tumors (pooled HR: 2.28; 95\% CI: $1.58-3.30)$, and there was significant heterogeneity found $\left(P<0.01, \mathrm{I}^{2}=82 \%\right)$, hence, a randomeffects model was utilized (Fig. 3). Subsequently, a sensitivity analysis was performed to explore the sources of heterogeneity. Exclusion of any individual study from the analysis did not significantly change the results (data not shown). Furthermore, a subgroup analysis was conducted based on various types of cancer to detect heterogeneity. The results indicated a negative effect of high ZEB-1 expression on OS (univariable analysis) in patients with colorectal cancer (pooled HR: 1.80; 95\% CI: 1.28-2.54) (Fig. 4a), esophageal squamous cell carcinoma (pooled HR: 1.71; 95\% CI: 1.38-2.13) (Fig. 4b) and pancreatic cancer (pooled HR: 1.63; 95\% CI: 1.19-2.23) (Fig. 4c). In addition, a similar result was found on OS (multivariate analysis) in patients with colorectal cancer (pooled HR: 2.75; 95\% CI: 1.65-4.56) (Fig. 5a), gastric cancer (pooled HR: 2.17; 95\% CI: 1.33-3.55) (Fig. 5b) and hepatocellular carcinoma (pooled HR: 2.07; 95\% CI: 0.73-5.92) (Fig. 5c). Additionally, subgroup analysis of OS according to different detection methods of ZEB-1 expression showed that high levels of ZEB-1 protein and mRNA expression were both correlated with poor OS in patients with solid tumors (Additional file 1).

\section{Publication bias}

In this study, Begg's funnel plot and Begg's test were performed to evaluate potential publication bias. The data indicated that there was no significant publication bias for OS in both the univariate (Fig. 6a) and multivariate analyses (Fig. 6b).

\section{Discussion}

ZEB-1 is a $190-210 \mathrm{kD}$ protein encoded by the TCF8 gene, which is an important inducer of EMT and characterized as the repressor of cell adhesion molecules as well as cell polarity correlative genes. [3,27] Numerous 
Table 1 General characteristics of studies included in the meta-analysis

\begin{tabular}{|c|c|c|c|c|c|c|c|c|c|c|c|}
\hline References & Country & $\begin{array}{l}\text { Cancer } \\
\text { type }\end{array}$ & Case No. & $\begin{array}{l}\text { Male/ } \\
\text { Female }\end{array}$ & $\begin{array}{l}\text { Age, } \\
\text { median }\end{array}$ & $\begin{array}{l}\text { Detect } \\
\text { method }\end{array}$ & Cut-off & $\begin{array}{l}\text { Follow-up } \\
\text { months (Range) }\end{array}$ & $\begin{array}{l}\text { Survival } \\
\text { analysis }\end{array}$ & $\begin{array}{l}\text { HR } \\
\text { obtained }\end{array}$ & NOS score \\
\hline $\begin{array}{l}\text { Yao.X.F } \\
/ 2017^{21}\end{array}$ & China & OCC & 120 & $75 / 45$ & 57.6 & $\mathrm{IHC}$ & score $\geq 7$ & $\begin{array}{l}66 \\
(8-116)\end{array}$ & OS (M) & Curve & 8 \\
\hline $\begin{array}{l}\text { Terashita.K } \\
/ 2016^{22}\end{array}$ & Japan & ICC & 102 & $63 / 39$ & 64 & $\mathrm{IHC}$ & score $>40$ & $\begin{array}{l}35 \\
(3-170)\end{array}$ & OS $(U)$ & Direct & 8 \\
\hline $\begin{array}{l}\text { Wu.D.W } \\
/ 2016^{10}\end{array}$ & China & CRC & 145 & $N R$ & $N R$ & $\mathrm{IHC}$ & score $>150$ & $\begin{array}{l}47.7 \\
(3.4-85.7)\end{array}$ & OS (M) & Direct & 7 \\
\hline $\begin{array}{l}\text { Goscinski.M } \\
/ 2015^{19}\end{array}$ & Norway & ESCC & 151 & $92 / 59$ & NR & $\mathrm{IHC}$ & staining > 50\% & 60 & OS $(U)$ & Curve & 7 \\
\hline $\begin{array}{l}\text { Murai.T } \\
/ 2014^{13}\end{array}$ & Japan & GC & 116 & $83 / 33$ & 64 & qRT-PCR & mRNA $\geq 0.0217$ & 60 & OS (M) & Curve & 7 \\
\hline $\begin{array}{l}\text { Yang.X.ZZ } \\
/ 2014^{20}\end{array}$ & China & ESCC & 100 & $69 / 31$ & 50 & $\mathrm{IHC}$ & score $>4.90$ & $\begin{array}{l}32 \\
(3-60)\end{array}$ & OS $(U)$ & Curve & 8 \\
\hline $\begin{array}{l}\text { Bronsert.P } \\
/ 2014^{17}\end{array}$ & Germany & PC & 112 & $55 / 57$ & 67 & $\mathrm{IHC}$ & score $\geq 2$ & 50 & OS $(U)$ & Direct & 7 \\
\hline $\begin{array}{l}\text { Hashiguchi.M } \\
/ 2013^{15}\end{array}$ & Japan & $\mathrm{HCC}$ & 108 & $85 / 23$ & 65.3 & $\mathrm{IHC}$ & staining $>1 \%$ & 60 & $\begin{array}{l}\text { OS }(U) \\
\text { OS (M) }\end{array}$ & $\begin{array}{l}\text { Direct } \\
\text { Direct }\end{array}$ & 8 \\
\hline $\begin{array}{l}\text { Zhang.G.J } \\
/ 2013^{11}\end{array}$ & China & CRC & 92 & $50 / 42$ & 65 & qRT-PCR & $>$ median value & 60 & $\begin{array}{l}\text { OS (U) } \\
\text { OS (M) }\end{array}$ & $\begin{array}{l}\text { Direct } \\
\text { Direct }\end{array}$ & 8 \\
\hline $\begin{array}{l}\text { Okugawa.Y } \\
/ 2012^{14}\end{array}$ & Japan & GC & 134 & $106 / 28$ & 67 & qRT-PCR & mRNA > 30.15 & $\begin{array}{l}23 \\
(1-79)\end{array}$ & $\begin{array}{l}\text { OS }(U) \\
\text { OS (M) }\end{array}$ & $\begin{array}{l}\text { Direct } \\
\text { Direct }\end{array}$ & 8 \\
\hline $\begin{array}{l}\text { Zhou.Y.M } \\
/ 2012^{16}\end{array}$ & China & $\mathrm{HCC}$ & 110 & $98 / 12$ & 54 & WB & expression> 30\% & 60 & OS (M) & Curve & 7 \\
\hline $\begin{array}{l}\text { Kurahara.H } \\
/ 2012^{18}\end{array}$ & Japan & PC & 76 & $52 / 24$ & 67 & $\mathrm{IHC}$ & staining $\geq 10 \%$ & 60 & OS $(U)$ & Curve & 7 \\
\hline $\begin{array}{l}\text { Singh.A } \\
/ 2011^{12}\end{array}$ & America & CRC & 250 & $136 / 114$ & 64.6 & gene chip & >median value & $\begin{array}{l}45 \\
(0.4-142)\end{array}$ & OS $(U)$ & Curve & 6 \\
\hline
\end{tabular}

Abbreviations: ZEB-1 zinc finger E-box-binding homebox 1, IHC immunohistochemistry, $q R T$-PCR quantitative real time polymerase chain reaction, WB western blotting, OS overall survival, $M$ multivariate analysis, $U$ univariate analysis, NR not reported, NOS Newcastle-Ottawa scale, OCC oral cavity carcinoma, ICC intrahepatic cholangiocarcinoma, CRC colorectal cancer, ESCC esophageal squamous cell carcinoma, GC gastric cancer, $P C$ pancreatic cancer, HCC hepatocellular carcinoma

Table 2 Quality assessment of eligible studies using the Newcastle-Ottawa Scale

\begin{tabular}{|c|c|c|c|c|}
\hline References & Selection & Comparability & Outcome & NOS \\
\hline Yao.X.F $/ 2017^{21}$ & $\star \star \star$ & $\star \star$ & $\star \star \star$ & 8 \\
\hline Terashita.K /2016 $6^{22}$ & $\star \star \star$ & $\star \star$ & $\star \star \star$ & 8 \\
\hline Wu.D.W $/ 2016^{10}$ & $\star \star \star$ & $\star$ & $\star \star \star$ & 7 \\
\hline Goscinski.M $/ 2015^{19}$ & $\star \star \star$ & $\star \star$ & $\star \star$ & 7 \\
\hline Murai.T $/ 2014^{13}$ & $\star \star \star$ & $\star$ & $\star \star \star$ & 7 \\
\hline Yang.X.Z /2014 20 & $\star \star \star$ & $\star \star$ & $\star \star \star$ & 8 \\
\hline Bronsert.P $/ 2014^{17}$ & $\star \star \star$ & $\star \star$ & $\star \star$ & 7 \\
\hline Hashiguchi.M $/ 2013^{15}$ & $\star \star \star$ & $\star \star$ & $\star \star \star$ & 8 \\
\hline Zhang.G.J $/ 2013^{11}$ & $\star \star \star$ & $\star \star$ & $\star \star \star$ & 8 \\
\hline Okugawa.Y $/ 2012^{14}$ & $\star \star \star$ & $\star \star$ & $\star \star \star$ & 8 \\
\hline Zhou.Y.M $/ 2012^{16}$ & $\star \star \star$ & $\star$ & $\star \star \star$ & 7 \\
\hline Kurahara.H $/ 2012^{18}$ & $\star \star \star$ & $\star \star$ & $\star \star$ & 7 \\
\hline Singh.A $/ 2011^{12}$ & $\star \star \star$ & $\star$ & $\star \star$ & 6 \\
\hline
\end{tabular}

Abbreviations: NOS Newcastle-Ottawa scale published studies indicated that EMT is an essential mechanism during tumor progression, invasion and metastasis. [28, 29] Unfortunately, metastases and invasions are highly characteristic of malignant tumors. Verschueren et al. [30] reported that ZEB-1 interacts with Smad proteins through mediation of transforming growth factor- $\beta$ signaling to facilitate EMT. Singh et al. [31] revealed that high expression of ZEB-1 may have an impact on cell-cell interactions resulting in endometrial cancer cell invasion and metastasis. The growth inhibitory effects of ZEB-1may repress the expression of members of the miR-200 family, which function as strong inducers of epithelial differentiation. [32, 33] Knockdown of ZEB-1 may induce cell apoptosis, while high ZEB-1 expression may drastically suppress lung cancer cells, as shown through soft agar colony formation assays. [34] Krishnamachary et al. [35] demonstrated that the expression of ZEB-1was regulated through the hypoxia-inducible factor $1 / \mathrm{E}$-cadherin signaling pathway in renal clear cell carcinoma. Moreover, other studies depicted the non-EMT functions of ZEB-1, indicating its critical role in regulating cell cycle progression, apoptosis, and senescence. [36] These previous studies demonstrated 


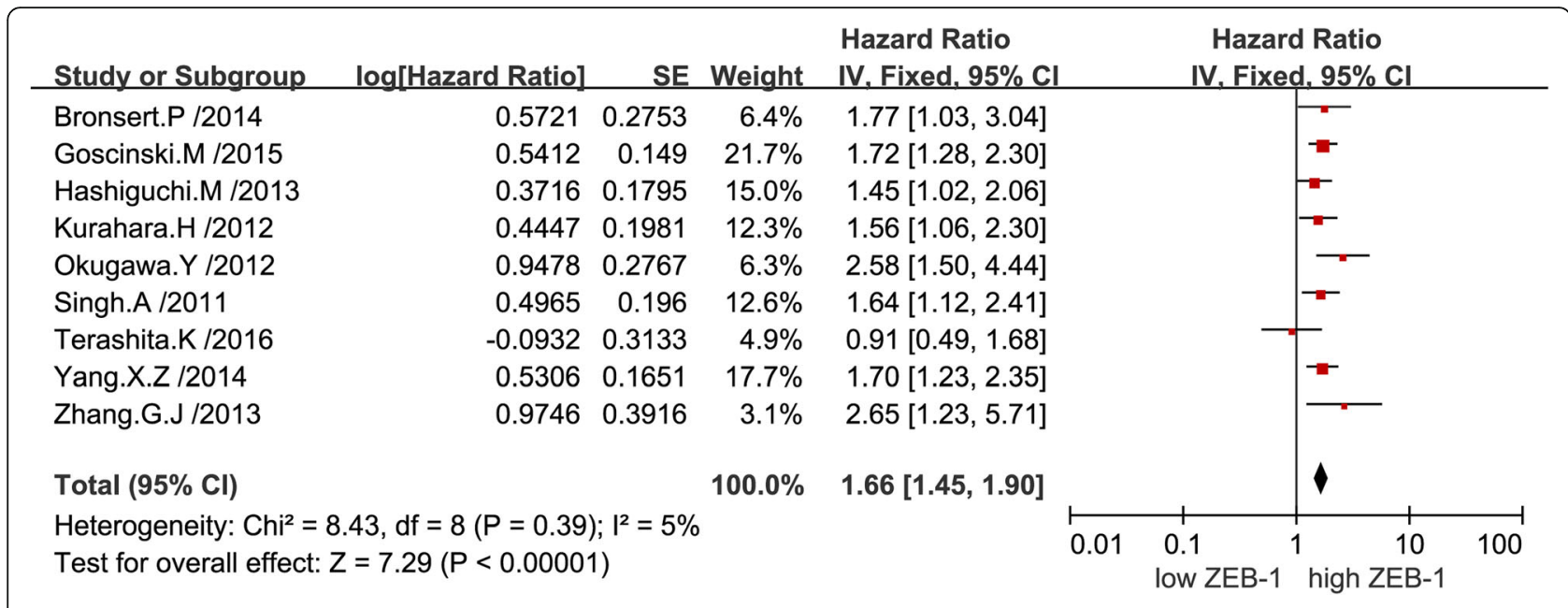

Fig. 2 Forest plots showing the relationship between ZEB-1 and OS (univariate analysis)

that ZEB-1is involved in the malignant progression of various types of human cancer through complicated molecular mechanisms.

An increasing number of research studies reported that the level of ZEB-1 expression has a crucial impact on patient survival. Yang et al. [20] reported that down regulation of ZEB-1 significantly reduced the invasive and migratory abilities of esophageal squamous cell carcinoma. In vitro, high expression of ZEB-1 was associated with poor OS in patients with esophageal squamous cell carcinoma. In gastric cancer patients, increased expression of ZEB-1 was markedly correlated with peritoneal dissemination and worse clinical prognosis. [14] Yao et al. [21] identified that high level of ZEB-1 expression was associated with recurrence, lymph node metastasis, worse pathologic grading and low survival rates in oral cavity carcinoma. Therefore, ZEB-1may serve as an effective prognostic marker and a promising novel therapeutic target in patients with solid tumors.
Accordingly, we conducted this meta-analysis to evaluate the prognostic value of ZEB-1.

In the present study, we systematically assessed the OS data of 1616 patients with solid tumors included in 13 eligible articles. The results provided strong evidence that overexpression of ZEB-1was significantly correlated with shorter OS in both univariate and multivariate analyses. Regarding the types of tumors, our study indicated that high expression of ZEB-1 was also significantly associated with worse OS in colorectal cancer, esophageal squamous cell carcinoma, pancreatic cancer, gastric cancer and hepatocellular carcinoma. This combined data analysis suggested that ZEB-1 may be a potential prognostic marker and therapeutic target for most solid tumors. Thus, it is essential to further investigate the clinical features and therapeutic implications of ZEB-1 expression in carcinomas.

This meta-analysis is characterized by several limitations. Firstly, only published studies and articles in English

\begin{tabular}{|c|c|c|c|c|c|c|c|c|}
\hline Study or Subgroup & log[Hazard Ratio] & SE & Weight & $\begin{array}{c}\text { Hazard Ratio } \\
\text { IV. Random. } 95 \% \mathrm{CI}\end{array}$ & \multicolumn{4}{|c|}{$\begin{array}{c}\text { Hazard Ratio } \\
\text { IV. Random. } 95 \% \mathrm{Cl}\end{array}$} \\
\hline Hashiguchi.M /2013 & 0.1823 & 0.1881 & $16.1 \%$ & $1.20[0.83,1.73]$ & \\
\hline Murai.T /2014 & 0.5653 & 0.1828 & $16.2 \%$ & $1.76[1.23,2.52]$ & \multirow{2}{*}{\multicolumn{4}{|c|}{-}} \\
\hline Okugawa.Y /2012 & 1.075 & 0.2808 & $13.4 \%$ & $2.93[1.69,5.08]$ & \multirow{2}{*}{\multicolumn{4}{|c|}{$\varpi$}} \\
\hline Wu.D.W /2016 & 1.1537 & 0.3362 & $11.9 \%$ & $3.17[1.64,6.13]$ & & & & \\
\hline Yao.X.F /2017 & 0.802 & 0.2561 & $14.1 \%$ & $2.23[1.35,3.68]$ & \multicolumn{4}{|c|}{$\varpi$} \\
\hline Zhang.G.J/2013 & 0.8065 & 0.4064 & $10.1 \%$ & $2.24[1.01,4.97]$ & \multirow{2}{*}{\multicolumn{4}{|c|}{$=$}} \\
\hline Zhou.Y.M /2012 & 1.2528 & 0.0942 & $18.3 \%$ & $3.50[2.91,4.21]$ & & & & \\
\hline Total $(95 \% \mathrm{Cl})$ & & & $100.0 \%$ & $2.28[1.58,3.30]$ & \multicolumn{4}{|c|}{$>$} \\
\hline $\begin{array}{l}\text { Heterogeneity: } \text { Tau }^{2}= \\
\text { Test for overall effect: }\end{array}$ & $\begin{array}{l}0.18 ; \mathrm{Chi}^{2}=32.44, \mathrm{df} \\
z=4.40(P<0.0001)\end{array}$ & $=6(P<$ & $=0.0001)$ & $2=82 \%$ & 0.01 & $\begin{array}{l}0.1 \\
\text { low ZEB-1 }\end{array}$ & $\begin{array}{l}1 \\
\text { high ZEB-1 }\end{array}$ & 100 \\
\hline
\end{tabular}




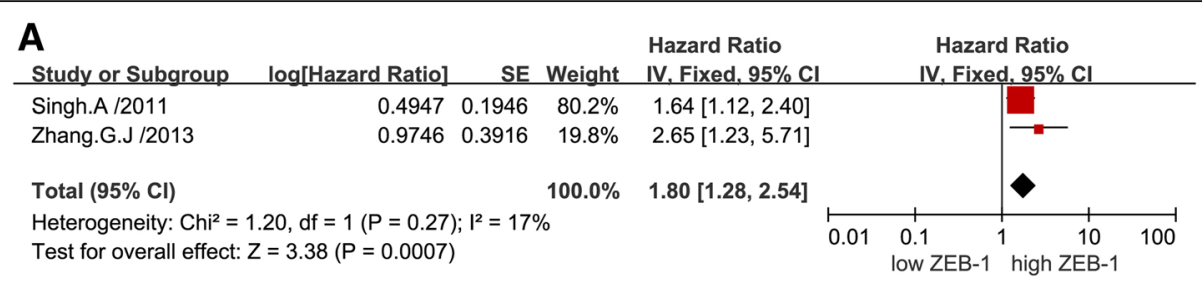

\section{B}

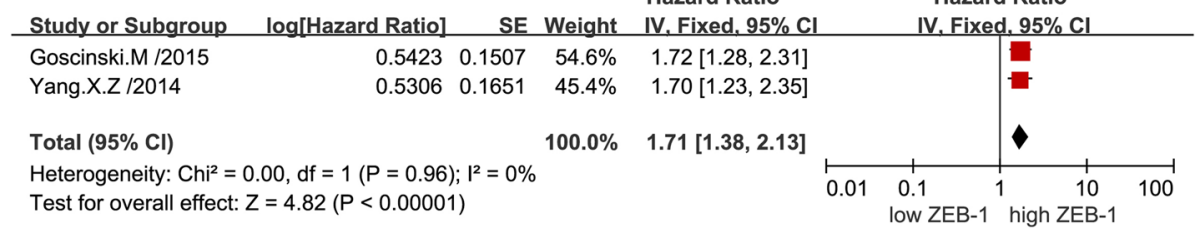

\section{c}

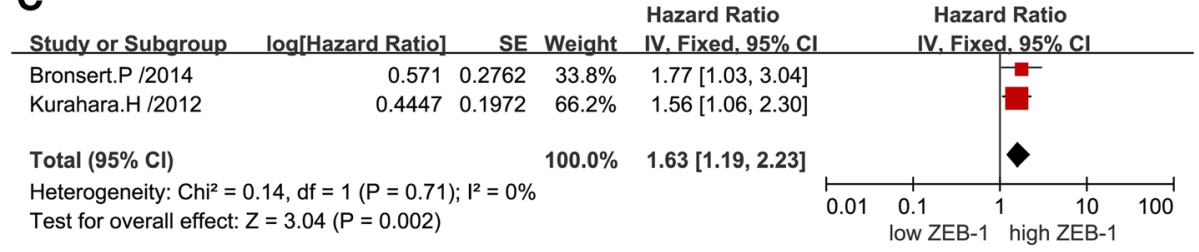

Fig. 4 Subgroup analysis of OS (univariate analysis) according to the expression of ZEB-1 in various types of tumors. Colorectal cancer (a); Esophageal squamous cell carcinoma (b); Pancreatic cancer (c)

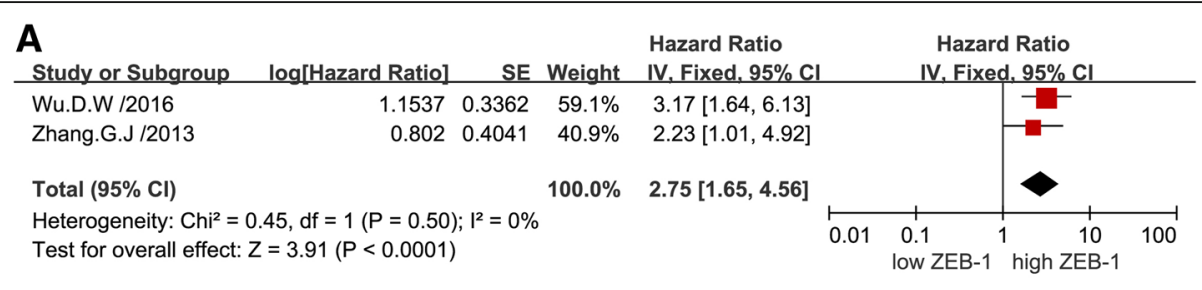

B

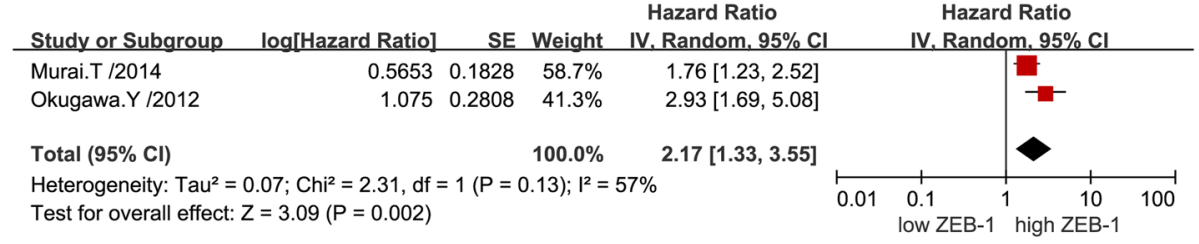

C

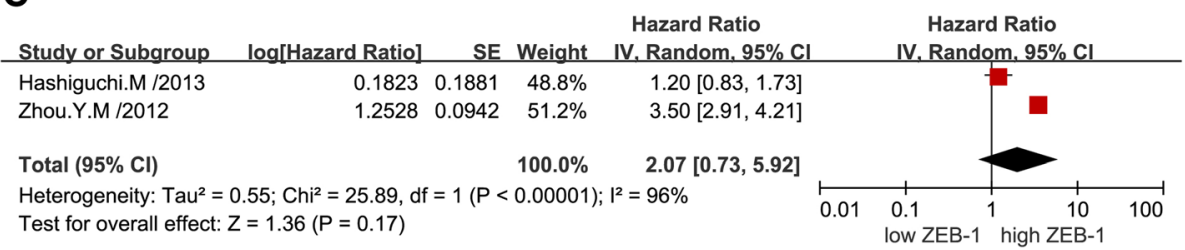

Fig. 5 Subgroup analysis of OS (multivariate analysis) according to the expression of ZEB-1 in various types of tumors. Colorectal cancer (a); Gastric cancer (b); Hepatocellular carcinoma (c) 

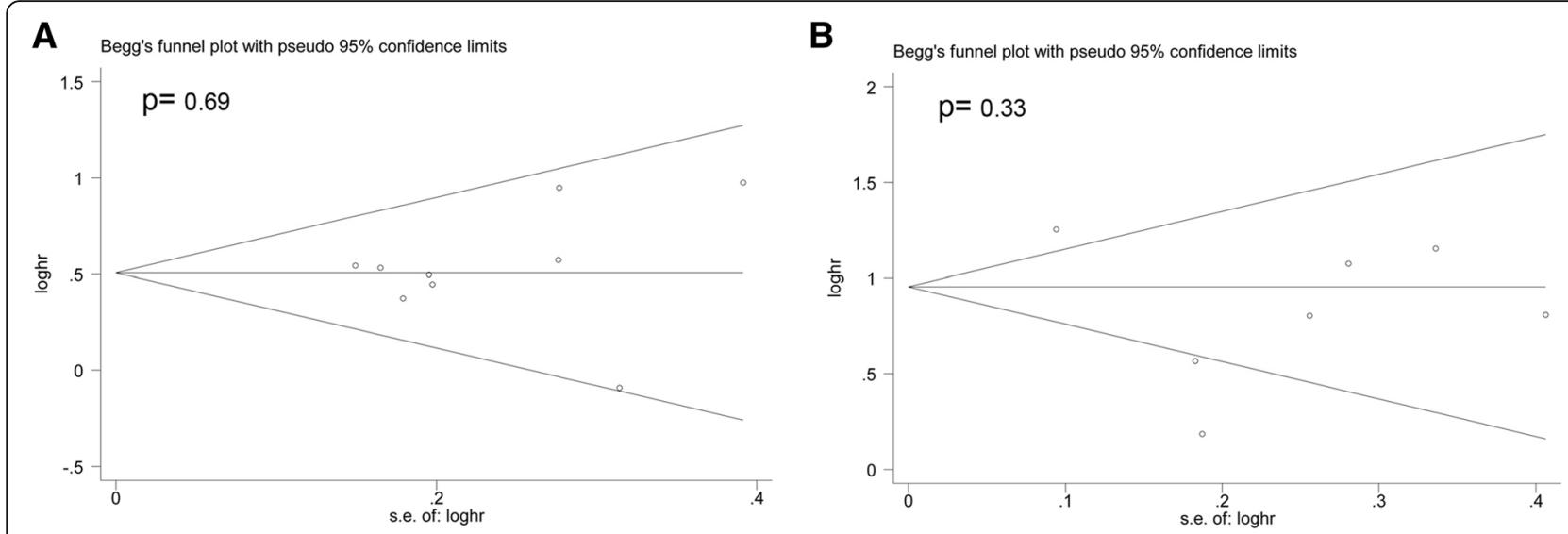

Fig. 6 Funnel plot evaluating potential publication bias for OS in the univariate (a) and multivariate (b) analyses

were included, and small sample studies with negative results may not have been published, which inevitably account for publication bias and selection bias. Secondly, the methods of measurement method and cut-off values for the evaluation of ZEB-1 expression were discordant. Finally, HR extracted from Kaplan-Meier curves appear to be no more reliable than those reported directly.

\section{Conclusions}

In conclusion, overexpression of ZEB-1 is correlated with poor OS in most solid tumors. This finding suggests that ZEB-1 may be a potential prognostic biomarker, and a novel therapeutic target in human solid tumors.

\section{Additional file}

Additional file 1: Subgroup analysis of overall survival according to different detection methods of ZEB-1. Protein (A) and mRNA (B) levels. (JPG $923 \mathrm{~kb})$

\section{Abbreviations}

Cl: Confidence intervals; EMT: Epithelial to mesenchymal transitions; HR: Hazard ratios; OS: Overall survival; ZEB-1: Zinc-finger E-box binding homeobox 1

\section{Acknowledgements}

We wish to thank everyone who helped with this study.

\section{Authors' contributions}

BRC and BSC designed and performed the study. BRC and ZPZ compiled the literature selection criteria and developed the literature search. BSC and WPY extracted the original data. JJZ, GL, and SJW performed the statistical analysis. $\mathrm{JG}$ and GXX processed the related figures and tables. BRC, BSC, and ZJH drafted the manuscript. All authors approved the final manuscript.

\section{Funding}

The design of this study was supported by the Medical Innovations Topic in Fujian Province (no.2016- CXB-8, 2012-CXB-29). The collection and analysis of data were supported by the Science and Technology Project of Natural Science Foundation of Fujian Province (No. 2016 J01639). The writing and revision of the manuscript were supported by the Youth Research Development Fund Project of The First Affiliated Hospital of Xiamen University (No. XYY2017010)
Availability of data and materials

The datasets used and analyzed in the present study are available from the corresponding author upon reasonable request.

Ethics approval and consent to participate

Not applicable.

\section{Consent for publication}

Not applicable.

\section{Competing interests}

The authors declare that they have no competing interests.

\section{Author details}

${ }^{1}$ Department of Gastrointestinal Surgery, Xiamen Cancer Hospital of The First Affiliated Hospital of Xiamen University, 55 Zhen Hai Road, Si Ming District, Xiamen 361003, Fujian Province, China. ${ }^{2}$ Department of Endoscopy Center, Xiamen Branch of Affiliated Zhongshan Hospital of Fudan University, Xiamen, Fujian, China. ${ }^{3}$ Department of Gastrointestinal Surgery, First Clinical Medical College of Fujian Medical University, Fuzhou, Fujian, China. ${ }^{4}$ Department of Breast Surgery, The Third Hospital of Nanchang City, Key Laboratory of Breast Diseases, Nanchang, Jiangxi, China. ${ }^{5}$ Department of Endoscopy Center, First Affiliated Hospital of Xiamen University, Xiamen, China.

Received: 1 November 2018 Accepted: 12 June 2019

Published online: 27 June 2019

\section{References}

1. Gheldof A, et al. Evolutionary functional analysis and molecular regulation of the ZEB transcription factors. Cell Mol Life Sci. 2012;69(15):2527-41.

2. Vandewalle C, Van Roy F, Berx G. The role of the ZEB family of transcription factors in development and disease. Cell Mol Life Sci. 2009;66(5):773-87.

3. Zhang PJ, Sun YT, Ma L. ZEB1: at the crossroads of epithelial-mesenchymal transition, metastasis and therapy resistance. Cell Cycle. 2015;14(4):481-7.

4. Zeisberg M, Neilson EG. Biomarkers for epithelial-mesenchymal transitions. J Clin Investig. 2009;1 19(6):1429-37.

5. Schmalhofer O, Brabletz S, Brabletz T. E-cadherin, beta-catenin, and ZEB1 in malignant progression of cancer. Cancer Metastasis Rev. 2009:28(1-2):151-66.

6. Aigner $\mathrm{K}$, et al. The transcription factor ZEB1 (delta EF1) promotes tumour cell dedifferentiation by repressing master regulators of epithelial polarity. Oncogene. 2007;26(49):6979-88.

7. Peinado H, Olmeda D, Cano A. Snail, ZEB and bHLH factors in tumour progression: an alliance against the epithelial phenotype? Nat Rev Cancer. 2007;7(6):415-28.

8. Hu F, et al. DeltaEF1 promotes breast cancer cell proliferation through down-regulating p21 expression. Biochim Biophys Acta. 2010; 1802(2):301-12

9. Jia BQ, et al. Overexpression of ZEB1 associated with metastasis and invasion in patients with gastric carcinoma. Mol Cell Biochem. 2012; 366(1-2):223-9. 
10. Singh AB, et al. Claudin-1 up-regulates the repressor ZEB-1 to inhibit Ecadherin expression in colon cancer cells. Gastroenterology. 2011;141(6): 2140-53.

11. Wu DW, et al. DDX3 enhances oncogenic KRAS-induced tumor invasion in colorectal cancer via the beta-catenin/ZEB1 axis. Oncotarget. 2016;7(16): 22687-99.

12. Zhang GJ, et al. High expression of ZEB1 correlates with liver metastasis and poor prognosis in colorectal cancer. Oncol Lett. 2013;5(2):564-8.

13. Murai $T$, et al. Epithelial-to-mesenchymal transition predicts prognosis in clinical gastric cancer. J Surg Oncol. 2014;109(7):684-9.

14. Okugawa Y, et al. Clinical significance of zinc finger E-box binding homeobox 1 (ZEB1) in human gastric cancer. J Surg Oncol. 2012;106(3):280-5.

15. Hashiguchi $\mathrm{M}$, et al. Clinical implication of ZEB-1 and E-cadherin expression in hepatocellular carcinoma (HCC). BMC Cancer. 2013;13.

16. Zhou YM, et al. Clinicopathological significance of ZEB1 protein in patients with hepatocellular carcinoma. Ann Surg Oncol. 2012;19(5):1700-6.

17. Bronsert $\mathrm{P}$, et al. Prognostic significance of zinc finger E-box binding homeobox 1 (ZEB1) expression in cancer cells and cancer-associated fibroblasts in pancreatic head cancer. Surgery. 2014;156(1):97-108.

18. Kurahara $\mathrm{H}$, et al. Epithelial-mesenchymal transition and mesenchymalepithelial transition via regulation of ZEB-1 and ZEB-2 expression in pancreatic cancer. J Surg Oncol. 2012;105(7):655-61.

19. Goscinski MA, et al. Nuclear, cytoplasmic, and stromal expression of ZEB1 in squamous and small cell carcinoma of the esophagus. APMIS. 2015;123(12): 1040-7.

20. Yang $X$, et al. Overexpression of zinc finger E-box binding homeobox factor 1 promotes tumor invasiveness and confers unfavorable prognosis in esophageal squamous cell carcinoma. Tumour Biol. 2014;35(12):11977-84.

21. Yao X, et al. Clinicopathological significance of ZEB-1 and E-cadherin proteins in patients with oral cavity squamous cell carcinoma. Onco Targets Ther. 2017; 10:781-90.

22. Terashita $\mathrm{K}$, et al. ZEB1 expression is associated with prognosis of intrahepatic cholangiocarcinoma. J Clin Pathol. 2016;69(7):593-9.

23. Stang A. Critical evaluation of the Newcastle-Ottawa scale for the assessment of the quality of nonrandomized studies in meta-analyses. Eur J Epidemiol. 2010;25(9):603-5.

24. Tierney JF, et al. Practical methods for incorporating summary time-to-event data into meta-analysis. Trials. 2007;8:16

25. Dickersin K, Berlin JA. Metaanalysis - state-of-the-science. Epidemiol Rev. 1992;14:154-76.

26. Higgins JPT, et al. Measuring inconsistency in meta-analyses. Br Med J. 2003; 327(7414):557-60

27. Miyazono K. Transforming growth factor-beta signaling in epithelialmesenchymal transition and progression of cancer. Proc Jpn Acad Ser B Phys Biol Sci. 2009;85(8):314-23.

28. Kalluri $R$, Weinberg RA. The basics of epithelial-mesenchymal transition. J Clin Investig. 2009;119(6):1420-8.

29. Thiery JP, et al. Epithelial-mesenchymal transitions in development and disease. Cell. 2009;139(5):871-90.

30. Verschueren $\mathrm{K}$, et al. SIP1, a novel zinc finger homeodomain repressor, interacts with Smad proteins and binds to 5 '-CACCT sequences in candidate target genes. J Biol Chem. 1999;274(29):20489-98.

31. Singh M, et al. ZEB1 expression in type I vs type II endometrial cancers: a marker of aggressive disease. Mod Pathol. 2008;21(7):912-23.

32. Oishi $\mathrm{N}$, et al. Transcriptomic profiling reveals hepatic stem-like gene signatures and interplay of miR-200c and epithelial-mesenchymal transition in intrahepatic cholangiocarcinoma. Hepatology. 2012;56(5):1792-803.

33. Wellner $\mathrm{U}$, et al. The EMT-activator ZEB1 promotes tumorigenicity by repressing stemness-inhibiting microRNAs. Nat Cell Biol. 2009:11(12):1487-U236.

34. Takeyama Y, et al. Knockdown of ZEB1, a master epithelial-to-mesenchymal transition (EMT) gene, suppresses anchorage-independent cell growth of lung cancer cells. Cancer Lett. 2010;296(2):216-24.

35. Krishnamachary B, et al. Hypoxia-inducible factor-1-dependent repression of E-cadherin in von Hippel-Lindau tumor suppressor-null renal cell carcinoma mediated by TCF3, ZFHX1A, and ZFHX1B. Cancer Res. 2006;66(5):2725-31.

36. Browne $G$, Sayan AE, Tulchinsky E. ZEB proteins link cell motility with cell cycle control and cell survival in cancer. Cell Cycle. 2010;9(5):886-91.

\section{Publisher's Note}

Springer Nature remains neutral with regard to jurisdictional claims in published maps and institutional affiliations.

Ready to submit your research? Choose BMC and benefit from:

- fast, convenient online submission

- thorough peer review by experienced researchers in your field

- rapid publication on acceptance

- support for research data, including large and complex data types

- gold Open Access which fosters wider collaboration and increased citations

- maximum visibility for your research: over $100 \mathrm{M}$ website views per year

At BMC, research is always in progress.

Learn more biomedcentral.com/submissions 